\title{
AMULETOS-TALISMANES PARA CABALLOS, EN FORMA DE CRECIENTE, EN LA ESPAÑA MEDIEVAL
}

\author{
POR \\ M. ${ }^{a}$ LUISA MARTÍN ANSÓN
}

\begin{abstract}
El presente estudio plantea una serie de cuestiones acerca de un grupo de piezas que se insertaban en el arnés del caballo. Entre ellas hay que considerar su significado, su empleo como adornos y como amuletostalismanes, así como la simbiosis experimentada en la forma de creciente y en los efectos producidos, fruto de la mentalidad de las gentes.
\end{abstract}

Palabras clave: amuletos; talismanes; caballos; creciente; España medieval.

This study puts forth a series of questions concerning a group of pieces which were inserted into the harnesses of horses in medieval Spain. Among the topics considered: their significance, their example as ornament and as amulets-talismans, the symbiosis which occurs in the crescent shape and the effects produced by these objects as the result of the mentality of the people.

Key words: amulets; talismans; horses; crescent shape; medieval Spain.

Amuletos y talismanes vienen a ser la consecuencia práctica e imprescindible del pensar mágico. El hombre, cuya imaginación estaba influida por ideas de magia se planteaba el problema de hallar el conjuro más apropiado entre los medios mágicos de que disponía. Un proverbio latino dice: Maleficia posse, per artem per quam facta sunt, destrui o lo que es lo mismo, el daño que hace el demonio sólo puede ser destruido por remedios demoniacos ${ }^{1}$. La cuna de estas prácticas, que son consustanciales a la historia del hombre, es realmente imposible de delimitar. Se ha intentado buscar raíces en diversos pueblos del antiguo Oriente. Los judíos miraron a Babilonia como su país de origen, pues en el Talmud Babilónico se dice que noventa y nueve personas mueren de mal de ojo por cada una que muere de muerte natural ${ }^{2}$. Los sacerdotes zoroástricos de Persia fueron conocidos por los griegos al menos en el siglo $\mathrm{v}$ a.C. y, al parecer, algunos de ellos emigraron al mundo mediterráneo ${ }^{3}$. Por otro lado, aunque se ha indicado que los helenos conquistaron a los judíos y fueron, a su vez, conquistados por la modificación judaica de sus sistemas filosóficos ${ }^{4}$, el verdadero papel jugado por el Judaísmo en el crecimiento del sistema religioso griego y romano está por documentar.

\footnotetext{
1 W. Born, «Fetiche, amuleto y talismán», Actas Ciba 1-2, 1944, (pp.1-32), p. 12.

2 E. Westermarck, Ritual and Belief in Morocco,London 1926, vol. I, p. 476.

${ }^{3}$ R. Kieckhefer, La magia en la Edad Media, Barcelona 1992, (ed.orig. 1989) p. 18.

${ }^{4}$ L.W. Moss y S. C. Cappannari, «Mal'occhio, Ayin ha ra, Oculus fascinus, Judenblick: The Evil Eye Hovers Above», en The Evil Eye, Ed. C. Maloney, N.York, 1976, p. 5.
} 
En cualquier caso, es muy probable que creencias y prácticas judías, fenicias o cartaginesas, con la colaboración del mundo romano, ejercieran considerable influencia sobre los musulmanes del Mediterráneo, pero supersticiones tan ampliamente difundidas no pueden atribuirse a un pueblo en particular, máxime, teniendo en cuenta que la similitud de rituales entre los pueblos semíticos, arios y mediterráneos, lleva a pensar en una amplia geografía con diversos núcleos. Además, hay que considerar que la celebración de rituales, el empleo de amuletos, talismanes, pantáculos, etc., dan respuesta a un valor universal del ser humano, como es la necesidad psicológica de prevención y protección, que afecta no sólo al hombre sino también a los animales y objetos. Así pues, amuletos, talismanes, etc. se convierten en símbolos tangibles de esperanza que fortifican el espíritu de quien los lleva ${ }^{5}$.

La historiografía referente a este tipo de objetos desde el punto de vista de las formas artísticas y su posible origen es ciertamente parca. Las publicaciones más interesantes al respecto, exceptuando las que se ocupan de aspectos oscurantistas, se realizan durante la primera mitad del siglo xx en que estas piezas produjeron una especial fascinación. Autores tan prestigiosos como Hildburgh les dedica un buen número de artículos, que iremos señalando a lo largo del trabajo, entre 1906 y 1951. No obstante, en la mayoría de ellos domina su curiosidad como coleccionista. Las piezas adquiridas por él, especialmente en España, permiten observar la pervivencia de modelos y creencias, prácticamente hasta nuestros días. Sin embargo, apunta que en seis años transcurridos entre sus visitas de 1906 y 1911 el número de amuletos ha decrecido, lo que atribuye a los avances de la educación y el progreso material ${ }^{6}$.

La consideración de amuleto-talismán va indefectiblemente unida a la de adorno o viceversa, de modo que pulseras, anillos, collares, ornamentos en los animales, etc. además de como señal de ostentación, servían de protección. No sólo la forma (creciente, cuernos, mano en distintas posiciones, estrella de David, etc.) sino también el material "en que se realizaban (metales, coral, azabache, piedras preciosas, etc.) tenían un carácter mágico. Bien conocidas son las piezas egipcias o sumero-babilónicas y, asimismo, son significativas algunas descripciones bíblicas como, por ejemplo, la que hace referencia a las mujeres de Jerusalén: ... Aquel día quitará el Señor el adorno de las ajorcas, los solecillos y las lunetas; los aljofares, las lentejuelas y los cascabeles; los peinados, las cadenillas de los pies, los ceñidores, los pomos de olor y los amuletos, los anillos y aretes de nariz; los vestidos preciosos, los mantos, los chales, los bolsos, los espejos, las ropas finas, los turbantes y las mantillas... (Libro de Isaías, 3, 16-24).

Según se recoge en el libro de Jueces (VIII, 26), los reyes Madiánicos llevaban crecientes y pendientes, incluso sus camellos tenían cadenas alrededor de sus cuellos: El peso de los anillos de oro que les había pedido, se elevo a mil setecientos siclos de oro, sin contar las lunetas, los pendientes y los vestidos de púrpura que llevaban los reyes de Madián, ni támpoco los collares que pendían del cuello de sus camellos.

Los Padres de la Iglesia se mostraron contrarios al exceso de ornamentación, no sólo por lo que indica de apego a los bienes materiales sino también por su condición de amuleto. Sin embargo, la herencia del mundo pagano era tan fuerte que se produjo una simbiosis difícil de deslindar. Los griegos, entre otras cosas, veneraban como amuletos las reliquias de sus héroes, hábito que trasmitieron a los romanos, una práctica de caracteres muy similares al culto a las reliquias de los santos, desarrollado por los cristianos.

El influjo ejercido por la luna, el mal de ojo o la fascinación, probablemente son las supersticiones más habituales y sus consecuencias se confunden, con frecuencia, en la mentali-

\footnotetext{
${ }^{5}$ W. L. Hildburgh, «Psychology underlyng the employment of amulets in Europe», Folk-Lore, vol. LXII, 1951 (pp. 231 251), p. 235.

${ }^{6}$ W. L. Hildburgh, «Collectanea. Further Notes on Spanish Amulets», Folk-Lore, vol. XXIV, n 1, 1913, p. 63.
}

$A E A$, LXXVIII, 2005, 309, pp. 5 a 21 
dad de las gentes. Las prácticas que pueden realizarse para prevenirlos o, en su defecto, combatirlos y curarlos, son numerosas. El mal causado por el pus visibo que fluye de la mirada puede tener efectos funestos, no sólo para el hombre sino también para los animales e incluso para los objetos inanimados. Virgilio en la tercera egloga de sus Bucólicas ${ }^{7}$, en el duelo poético entre los dos pastores, pone en boca de Menalcas lo siguiente: He aqui que para estos otros ni siquiera es el amor la causa de que estén en los huesos. Un ojo -y no sé yo cuálinfluye en la vida de mis pobres corderos.

Las repercusiones del influjo lunar, conocido también como mal de aire ${ }^{8}$ son similares a las del mal de ojo Sin embargo, parece evidente que desde el principio de los tiempos, la luna, en sus diversas fases, fue objeto de una mezcla de veneración y temor, dada su condición de reina de la noche, diosa de la fertilidad y, al mismo tiempo, diosa de los muertos. Según todos los indicios, el amuleto lunar que refleja la fase de los dos cuernos tiene un mayor poder de contrarresto que el que representa la más amable cara de la luna llena, lo que justificaría el elevado numero de crecientes ${ }^{9}$. El influjo lunar, en la mente popular, está íntimamente asociado al mal de ojo y ambos requieren una práctica preventiva, pues el enemigo oculto es de tal índole que se debe estar siempre en guardia contra él ya que, además, la acción dañina, una vez realizada, es prácticamente incurable ${ }^{10}$.

Estas convicciones fueron comunes entre musulmanes, judíos y cristianos, no llegando a erradicarse en ningún momento. El Profeta, sin duda, la heredó de sus antepasados árabes que la compartían con los pueblos semíticos, de modo que estas creencias están reconocidas en el Korán.: Cap. CXIII, 1-5: Di: Yo me acojo al Señor del alba de la mañana para que me salve. De la malicia de los seres que ha creado. Y del mal a que nos expone la luna cuando se esconde y se oscurece la noche... Y de la malicia del individuo que nos tiene envidia. Cap. CXIV, 4-6: ... De la malicia del que sugiere los malos pensamientos ocultamente. Del que infunde el mal en los corazones. De los genios y de los hombres.

Algunos comentaristas del Korán refieren que el propio Mahoma llegó a ser víctima del mal de ojo, pero que Ala le protegió. La base se encuentra en el Cap. LXVIII, 52: En verdad poco falta para que los infieles no te echen de tu sitio con sus miradas, cuando ellos oyen leer el Korán, y dicen: Ciertamente, este es un endemoniado; pero este Korán no es más que la amonestación para todas las criaturas. Para otros, el mal de ojo forma parte del orden establecido por la Providencia e incluso, se cree que el mal de ojo disputa a los muertos el reposo de su última morada ${ }^{11}$.

El conocido filósofo y teólogo musulmán Algazel († 1111) en su obra Intenciones de los filósofos, traducida al latín en la escuela de Toledo, dice que las almas de algunas personas pueden llegar, en su influjo sobre otros cuerpos humanos, hasta el extremo de alterar o destruir su espíritu vital, mediante una simple operación de la fantasía, y así hasta matar a un hombre. Y esto es lo que significa el mal de ojo. Y por eso dijo Mahoma: en verdad que el ojo puede meter al hombre en el sepulcro y al camello en la marmita. Y en otra ocasión añadió: el mal de ojo es una verdad ${ }^{12}$.

En pleno siglo XIV, Ibn Khaldun, considerado uno de los más grandes sabios de su tiempo, que fuera embajador en la corte de Pedro I de Castilla, en 1364, describe el mal de ojo diciendo: Los efectos producidos por el mal de ojo, se incluyen en el número de impresiones que

\footnotetext{
${ }^{7}$ Virgilio, Obras completas, Trad. E. Gómez de Miguel, Madrid; s.a. p. 38.

${ }^{8}$ C. Alarcón Román, Catálogo de amuletos del Museo del Pueblo Español, Madrid, 1987, p. 16.

${ }^{9}$ R. T. Günther, M.A., F.L.S., «The Cimaruta: Its Structure and Development», Folk-Lore, vol. XVI, n. ${ }^{\circ} 2$, p. 141.

${ }^{10}$ R. Salillas, La fascinación en España, Madrid, 1905, pp. 70-71.

11 J. Desparmet, Le mal magique. Alger-Paris, 1932, cap. V, pp. 81- 113.

12 G. J. de Osma, Catálogo de azabaches compostelanos. Madrid, 1916. (Ed. facsímil, Consorcio de Santiago, 1999), p. 10 .
}

AEA, LXXVIII, 2005, 309, pp. 5 a 21 
resultan de la influencia del alma. Proceden del individuo dotado de la facultad del mal de ojo, y tienen lugar cuando él ve una calidad o un objeto cuyo aspecto le causa placer. Entonces, su admiración se vuelve tan intensa, que hace nacer en su entraña un sentimiento de envidia, juntamente al deseo de arrebatar esa calidad o ese objeto a quien lo posee. Entonces aparecen los efectos perniciosos de dicha facultad, o sea, del mal de ojo. Facultad ingénita, debida a la organización del individuo ${ }^{13}$. Él mismo parece haber sido objeto de este mal cuando efectuó su segundo viaje a Andalucía ${ }^{14}$.

Gran importancia se da a la creencia en el mal de ojo en época Talmúdica y algo similar se aprecia en la literatura midrásica. En la Biblia hebrea el mal de ojo como poder destructivo o independiente no es predominante. No obstante, algunas referencias permiten vislumbrar la presencia de estas creencias. En el Deuteronomio (28,54- 56), por ejemplo, encontramos el mal de ojo como expresión de comportamiento despiadado .... La más delicada y tierna de las mujeres de tu pueblo, tan delicada y tierna que no hubiera osado posar en la tierra la planta de su pie, mirará con malos ojos al esposo de su corazón, e incluso a su hijo y a su hija...Del mismo modo, un uso activo del ojo mediante una intensa mirada se encuentra en Samuel (18, 8-9): Irritóse mucho Saúl y le disgustó el suceso, pues decía: Dan miríadas a David y a mi millares; sólo le falta ser rey. Y desde aquel día en adelante miraba Saúl a David con ojos de envidia...

En opinión de los autores que han tratado el tema, parece más bien que es en la literatura rabínica donde se interpreta este modo de usar el ojo, sirviendo de base la mayoría de las expresiones alusivas al concepto de ojo en la Biblia, para la exégesis rabínica ${ }^{15}$. Por otra parte, no hay duda en el valor del término tal como aparece en las inscripciones de los amuletos judíos, especialmente desde la Edad Media y el hecho de que los judíos incorporen en la oración de la mañana una invocación para la protección contra el mal de ojo, certifica esta práctica. Además, la existencia de especialistas consagrados a la curación de este estado indica hasta que punto la creencia estaba arraigada ${ }^{16}$.

No obstante, el acercamiento judío a la protección contra el mal de ojo se basa especialmente en la creencia en el Poder de las Palabras, mediante la inscripción de los Nombres de Dios, de los ángeles y de las citas bíblicas. La lengua hebrea, considerada en sí misma un elemento mágico, se creía que era la única lengua entendida por los ángeles ${ }^{17}$. Especialmente durante la Edad Media, las fórmulas hebreas fueron adoptadas e insertas, asimismo, en amuletos-talismanes cristianos y musulmanes, probablemente porque muchos de ellos eran encarga-

13 J. Gautier Dalché, «Ibn Khaldoun et son temps», en Ibn Khaldun. Colloque. Mai 1962. Faculté des Lettres et des Sciences Humaines. Université Mohammad V. Casablanca, pp. 33-38. F. Alemán Picatoste, El mal de ojo. Historia clínica y tratamiento. Discurso de ingreso. Real Academia de Medicina y Cirugía de Murcia. 20 de marzo de 1987 , p. 16.

${ }_{14}$ Ibn Khaldûn, Le voyage d'Occident et d'Orient. Trad. A. Cheddadi. Paris, 1980, pp. 92 y 140. Cuenta cómo los favores de que gozaba por parte del sultán llegaron a excitar contra él los demonios de su envidia y cómo, mediante ciertas acusaciones, los altos dignatarios veían con mal ojo su instalación en Andalucía, llegando a pedir su extradición al sultán andaluz.

${ }^{15}$ R. Ulmer, The evil eye in the Bible and in Rabbinic Literature, U.S.A., 1994, pp. 4-5.

${ }^{16}$ A. Dundes, The Evil Eye: a casebook, London, 1992, p. 47. Entre las fuentes judías se consideran dos teorías respecto al mal de ojo. La más antigua es la teoría de los espíritus, basada en la creencia de que numerosos espíritus del mal existen en el ojo que, en determinadas ocasiones, bajo provocación, pueden herir a otros, causando enfermedad e incluso la muerte. Probablemente la practica de cubrir los ojos del difunto con piezas de porcelana sea para guardarse del revoloteo de los malos espíritus en ellos. Plegarias para proteger de estas influencias demoniacas y del mal de ojo, fundamentan su entrada en la liturgia judía. La segunda teoría es la de la evaporación en la que se considera que el ojo, como la piel, tiene poros a través de los cuales evapora algunos desperdicios. Este vapor es altamente venenoso y puede producir la enfermedad e incluso la muerte. Según esta teoría todo el mundo tiene el poder de dominar con la vista, p. 50.

Es curioso un herbario del siglo xIV que cuenta cómo San Agustín aprendió los poderes para alejar a los espíritus malignos y, entre sus miniaturas, incluye una que muestra al santo recomendando una hierba para realizar el exorcismo, conocida, entre otros, con el nombre de hierba de Salomón. R. Kieckhefer, 1992, pp. 86-87.

${ }_{17}$ T. Schrire, Hebrew Amulets. Their decipherment and interpretation. London, 1966, p. 70.

$A E A$, LXXVIII, 2005, 309, pp. 5 a 21 
dos a artesanos judíos, dada su cualificación de excelentes joyeros y orfebres y ellos, no enteramente convencidos de los efectos beneficiosos de sus propios productos, consideraban prudente reforzar sus virtudes añadiendo algunas inscripciones hebreas.

Si bien en el Antiguo Testamento se menciona el uso de amuletos, el cristianismo luchó contra ello, pero la costumbre estaba tan arraigada que tuvo que ceder, permitiendo llevar trozos de la Vera Cruz o cintas con sentencias evangélicas. Incluso, surgió una nueva categoría de amuletos cristianos, tanto en el mundo latino como en Asia Menor, Arabia y Etiopía. La Iglesia instituyó los Agnus Dei, trocitos de cera bendecidos y moldeados en forma de bola, con un Cordero Pascual y una invocación piadosa. A veces era una bola de oro adornada con una cruz, durante mucho tiempo en forma de Tau. El crismón, las filacterias con inscripciones piadosas, el nombre de la Virgen, el Ave María e incluso el nombre de Cristo mezclado con nombres divinos gnósticos y hebreos, han sido muy utilizados como talismanes cristianos ${ }^{18}$.

La herencia pagana, los intercambios culturales y la unidad de pensamiento al respecto, determinarán con frecuencia la creación de amuletos-talismanes formados a base de la combinación de distintos temas (creciente, mano de Fátima, mano en forma de higa, estrella de David, sello de Salomón, etc.). En ellos se suele hacer referencia a la Virgen mediante la inclusión de una letra «M», en caracteres góticos, usada como abreviatura de María ${ }^{19}$ y la flor de cuatro pétalos, asociada a la llamada rosa de Jericó, que se considera su emblema. Esta tiene siempre un significado femenino, lo mismo que la luna. Es flor de una planta que nace en los desiertos de Siria, cuyas ramas y flores, al parecer muertas, reviven en cuanto reciben un poco de humedad. A veces, se ha confundido con la rosa de escaramujo o rosa casina. Además, no hay que olvidar el empleo del creciente como emblema usado constantemente asociado a la Virgen, que tiene como fuente la mujer que San Juan describe en el Apocalipsis (12, 1-2).

La Iglesia no fue capaz de combatir estas creencias a pesar de que reiteradamente, en sucesivos concilios, lucho contra ellas. Todavía en pleno siglo xiII, algunos teólogos cristianos, como Santo Tomás de Aquino (Summa Theologica, Pars.I, q.117, a.4) o Roger Bacon (Opus Majus) admitían el mal de ojo como hecho, como fenómeno natural. Los textos son explícitos en el II Concilio de Braga (572). El Decreto LXXI establece que no es lícito a los cristianos prestar atención a las diversas supersticiones y el siguiente (LXXII) precisa que no lo es guardar las tradiciones de los gentiles o guiarse por el curso de la luna o las estrellas: No está permitido a los cristianos el conservar las tradiciones de los gentiles ni festejarlas, ni tampoco tomar en cuenta los elementos, o el curso de la luna, o de las estrellas, o la vana falacia de los astros, para la construcción de su casa, o para la siembra o plantación de árboles, o para la celebración del matrimonio, pues está escrito: Todo lo que hacéis, sea de palabra, sea de obra, hacedlo en nombre de nuestro Señor Jesucristo dando gracias a Dios. En el IV Concilio de Toledo (633) la amonestación va dirigida a los clérigos que consultan a los magos o adivinos ${ }^{20}$.

Ya en la segunda mitad del siglo XIII, en el Concilio de León del año 1267 se establece pena de excomunión en los siguientes términos: Defendemos so pena de descomunion, que ningun clerigo non sea encantador, nen adevinador, nen sortorero, nen aqueyador, nen faga cartar per aponer al cuello, et que esto mismo defienda a sos feligreses. Más explicíto es, si cabe, el Concilio de Valladolid del año 1322 que en el Decreto XXV dice: ... Prohibimos además bajo pena de escomunión que nadie dé crédito a los agüeros, ni se rija por el consejo de los agoreros en lo que tenga que hacer. Los prelados y los predicadores de la palabra de Dios desengañaran a los cristianos en sus sermones sobre la falsedad de los agüeros. En términos simi-

\footnotetext{
18 J. Rivière, Amuletos, talismanes y pantáculos. (ed. orig. Paris, 1972) Barcelona, 1974, pp. 153, 164-165.

19 W. L. Hildburgh, «Collectanea. Notes on Spanish Amulets (Third Series)», Folk-Lore, n. ${ }^{\circ}$ XXV, 2, 1914 , p. 208.

20 J. Vives, Concilios visigóticos e hispano-romanos, Barcelona-Madrid, 1963, pp. 103 y 203.
} 
lares se recoge, todavía, en Concilios posteriores, como en el Decreto XV del Concilio de Salamanca del año $1335^{21}$.

La posesión de amuletos de distintas formas, materiales, colores, etc. será, pues, una práctica fundamental para combatir los diferentes males. El efecto del amuleto puede ser preservativo, conjurativo o de acción directa y curativo, pudiendo distinguirse diversos tipos como los crómicos, los odoríficos, etc. Una característica generalmente común será la forma penetrativa, capaz de rasgar el maleficio envolvente y de matar la mirada maléfica. El amuleto contra el mal de ojo debe llevarse al descubierto, los contrarios a la fascinación pueden colocarse en el interior. La diferencia entre ambos males es muy sutil por lo que, a veces, se confunden. Como se ha podido observar, con frecuencia a lo largo de este estudio, se une a la palabra talismán, objeto manipulado siguiendo ciertas pautas de tipo mágico. Frente al carácter pasivo del amuleto como protector contra el mal, al talismán se le supone una protección activa y, sin duda, esta doble función era cubierta por la mayoría de los colgantes usados durante la Edad Media tanto en personas como en animales.

Intentar recoger creencias, prácticas, tipologías, etc. sería realmente una labor que excede con mucho los límites previstos para este trabajo. Por ello, nos vamos a centrar en una serie de amuletos- talismanes con forma de creciente, correspondientes a los siglos XIII-XIV, que servían para la protección de los caballos, así como para dotarles de fuerza y vigor. La forma de suspensión del creciente en los amuletos utilizados en seres humanos suele ser vertical, de modo que una simple anilla se fija en la parte alta, mientras que los crecientes de bronce usados por animales (asnos, caballos, vacas, etc.) se cuelgan con la cara hacia abajo, en una posición apropiada al paso de los cuadrúpedos e idéntica a la de los crecientes representados en estatuas de su divinidad protectora, Diana de Efesos.

Este tipo de objetos se usó en Europa ya desde la Edad de Piedra pero seguramente fueron los romanos quienes los difundieron a través de todo el imperio influyendo de modo decisivo en el desarrollo de estas prácticas ${ }^{22}$. La evolución de las formas ha sido tan escasa que, en ocasiones, se plantean dudas de cronología.

El equipamiento del caballo romano, al parecer adoptado de la caballería céltica, lo conocemos especialmente a través de la escultura funeraria y, en menor medida, de la escultura oficial ${ }^{23}$. En ambos casos es notoria la presencia de pinjantes y, entre sus formas, son significativos los lunados. Las lunulae muestran diversas formas: planas, con terminaciones bulbosas, con perfil angular, con perfil curvo, etc., son extremadamente comunes y se encuentran desde el período de Augusto a través del siglo II d.C. unidas al arnés del caballo. Una de las obras en las que llega a su punto más alto la representación escultórica del equipamiento del caballo es el monumento funerario de Flavius Bassus (Museo de Colonia) (Fig. 1), donde los pinjantes lunulados cuelgan de los correajes de la grupa, del petral e, incluso, desde la frontaleda, sobre la frente del animal, mientras su crin está atada en un penacho. En cuanto a la escultura oficial, citemos solamente la columna de Trajano ya que, entre los ochenta y dos caballos romanos representados en ella, hay cuatro variedades de disposición de arnés. Los pinjantes son generalmente trifoliados, excepto en el petral, donde aparece con frecuencia una

${ }_{21}$ J. Tejada y Ramiro, Colección de Canones y de todos los Concilios de la Iglesia Española. Madrid 1851, t. III, pp. 390, 503, 576.

${ }^{22}$ T. Schrire, 1966, p. 8. Conocidos son algunos ídolos púnicos del cielo que se distinguen por sus collares llenos de estrellas, así como el simbolismo lunar de Tanit, principal divinidad de Cartago, atestiguado por la presencia de un creciente en sus estelas y confirmado por el nombre de Juno Caelestis con que se conoce en época romana. Del mismo modo, Baal era, a menudo, invocado, considerándose todavía en algunas regiones el gesto conocido como Cuernos de Baal, hecho con los dedos índice y meñique, una segura protección contra el mal de ojo.

${ }^{23}$ Ver, entre otros: M. C. Bishop, «Cavalry Equipment of the Roman Army in the First Century A.D.», Military Equipment and the Identity of Roman Soldiers, Ed. J.J. Coulston. B.A.R. International Series, 394, 1988, pp. 67-195.

A. Hyland, Equus. The Horse in the Roman World, London 1990.

$A E A$, LXXVIII, 2005, 309, pp. 5 a 21 
lunula. En la mayoría de las ocasiones eran de cobre con aleación de bronce, a veces plateados y embutidos con nielo.

Los caballos, cuya finalidad primordial en el mundo antiguo era la carrera o la guerra, ya por su propio color tenían un significado especial según recoge San Isidoro ${ }^{24}$. Corrían en distintas estaciones del año y sus carreras se dedicaban a los cultos de diferentes dioses. Seguramente, esta vinculación a las divinidades, contribuía a que fueran objeto de especial cuidado $\mathrm{y}$, es evidente, que una forma de protección y participación de energías positivas era el empleo de amuletos- talismanes que, colocados en el caballo le previenen del mal de ojo al mismo tiempo que le dan fuerza y resistencia y, en su caso, favorecen la fertilidad.

El gusto por el lujo en el arnés, incluso con incrustaciones de marfil, oro o piedras preciosas, esta testimoniado desde antiguo en autores como Homero, Juvenal, Tito Livio, Virgilio, etc. La suspensión de estos adornos (phalerae) con valor ornamental, de identificación de condición social o posesión y, en su caso, de amuletos, en el enjaezamiento de los caballos, se remonta, igual que en el hombre, a los tiempos más remotos, según se aprecia en pinturas, relieves, miniaturas, marfiles, etc. La secuencia puede seguirse a lo largo de toda la Edad Media, con variedad de temática, motivos ornamentales, heráldicos, etc., tanto en Occidente como en Oriente ${ }^{25}$. En el caso que nos ocupa, faleras en forma de creciente podemos observar, por ejemplo, en miniaturas del Beato de Liébana (Fig. 2) o del Beato de Fernando I lo mismo que en un icono bizantino del siglo XII que muestra a San Demetrio a caballo (Fig. 3). No obstante, esta práctica, si bien no en todas las ocasiones con la misma riqueza y lujo de materiales, afectaba a todo tipo de animales, en particular domésticos y de carga pues, es conocido que desde tiempo inmemorial, principalmente a la bestia que guía la manada, se le cuelga al cuello una garceta, es decir, la primera punta del cuerno del venado ${ }^{26}$.

Durante la Edad Media, cristianos, musulmanes y judíos, indistintamente, los pusieron sobre los animales domésticos e incluso sobre los árboles, en cuya protección juega un papel importante el color rojo, según costumbre romana atestiguada. Entre los judíos, algunas de las divisas más usadas por los animales eran la cola de zorro o un penacho carmesí colocados entre sus ojos, pero amuletos y talismanes, aunque contuvieran inscripciones bíblicas o el nombre de Dios no podían usarse en sabat: No se sacan los caballos con cola de zorro ni con (un adorno) brillante entre los ojos. Un caballo no debe ir con cola de zorro o con cinta carmesí entre sus ojos. Una vaca no debe ir con su bozal y los potros no con sus bolsas de pienso ni las cabras con bolsas en sus ubres. Un animal no debe salir llevando sandalias en los cascos ni amuletos aun cuando esté atestiguada (su eficacia). Esta norma no es tan estricta para los animales como para los humanos ${ }^{27}$. El color rojo de estas divisas tenía, además, una función

\footnotetext{
${ }^{24}$ San Isidoro de Sevilla, Etimologías, Ed. J. Oroz Reta y M.A. Marcos Casquero, B.A.C. Madrid, 1983, pp. 414- 417, los gentiles, fijándose en las causas de los elementos, pusieron los de color alazán en relación con el sol, es decir, con el fuego; los blancos con el aire; los verdosos, con la tierra y los azulados, con el mar.

${ }_{25}$ M. ${ }^{a}$ L. Martín Ansón, «Adornos metálicos en los caballos: pinjantes y aplicaciones», Archivo Español de Arte, Madrid, núm 199, 1977, pp. 297-312.

Esmaltes en España, Artes del tiempo y del espacio. Madrid 1984.

«Algunos pinjantes góticos en el M.A.N.», Boletín del Museo Arqueológico Nacional, Madrid, vol.III, núm. 2, 1985, pp. 151-155.

«La colección de pinjantes del Museo Lázaro Galdiano», Goya, Madrid, núm. 193-195, 1986, pp. $57-65$.

Catàleg de xapes de guarniment. Fons del Museu Frederic Marès. Barcelona, 1994

«Los pinjantes del Museu Marès», Barcelona Metropolis Mediterrania, n. ${ }^{\circ}$ 27, pp. 78-79.

«Pinjantes» en Mil años del caballo en el arte hispánico, Sevilla 2001, pp. 64-65 y 82-86.

${ }^{26}$ C. Baroja, 1945, p. 14. I. del Pan, «Un curioso amuleto empleado contra el mal de ojo en los borricos en algunas regiones españolas», Actas y Memorias de la Sociedad Española de Antropología, Etnografía y Prehistoria, t. III, 1924, pp. 47-55.

${ }^{27}$ El Talmud de Babilonia. Tratado Sabat, ed. A.J. Weiss, Buenos Aires, 1971, 53a, cap. V, p. 212. En nota n. ${ }^{\circ} 42$, se la colgaban entre los ojos para ahuyentar el mal de ojo.
} 
protectora adicional, ya que se creía que el rojo y el azul tenían estos valores protectores intrínsecos.

La variedad de prácticas, formas y objetos empleados en la protección del caballo es considerable. En ocasiones se colgaban de su cuello o entre sus ojos, campanillas o cascabeles que, además de ejercer función protectora y proporcionar placer musical, avisaban a los transeúntes de la proximidad de un tiro de animales. Aunque la razón no está clara, se relaciona con la frase recogida en Zacarías (14, 20): Aquel día se hallara en los cascabeles de los caballos: Consagrado a Yahveh... También, en algunos países como Italia, las conchas de distintos tipos de moluscos cuentan entre los amuletos que protegen al caballo y propician su fertilidad ${ }^{28}$. Práctica habitual, especialmente en Gran Bretaña, era el uso de una piedra horadada, enganchada a la llave de la puerta del establo que se usaba para proteger a los caballos de los encantamientos de duendes y brujas ${ }^{29}$. La creencia de que el mal de ojo, provocado especialmente por un sentimiento de envidia, recae de modo especial sobre los seres, objetos, etc. bellos y perfectos, lleva, en algunos casos, como el de los beduinos, a cortar las orejas de sus caballos. Es una especie de sacrificio de redención. Mutilan ligeramente una bestia para que no corra los peligros a los que la expondría una perfección absoluta ${ }^{30}$.

España participó y aún participa de forma activa en la creación y uso de este tipo de objetos desde los tiempos más remotos Los amuletos profanos españoles muestran grandes semejanzas, especialmente, con los italianos y portugueses ${ }^{31}$, sin duda derivado de los resultados de la colonización romana pero, junto a ello, hay que anotar las también relevantes influencias fruto de la dominación musulmana y la mezcla con símbolos del cristianismo en un intento de cristianizar practicas paganas contra las que las prohibiciones resultaban estériles.

A la influencia de la luna se atribuían y, aún hoy, se atribuyen numerosos males por lo que la forma de creciente, sin duda, es una de las más apreciadas. Según Hildburgh ${ }^{32} \operatorname{los}_{\text {crecientes }}$ lunares en España tienen dos intenciones, por un lado luchar contra el mal de ojo y, por otro, proteger frente a una especie de influencia lunar que, en la mente popular, está fuertemente asociada al mal de ojo. Por el contrario, las influencias del sol se consideraron siempre beneficiosas ya que mata a los invisibles que dejan al hombre ciego e indefenso. En las tinieblas está todo lo malo que nos rodea; el aire y los espíritus del mal; el misterioso poder de éstos no resiste la mirada luminosa del sol. Como las puntas agudas de los cuernos de coral o de azabache, sus rayos rompen las influencias maléficas. Sin embargo, la figura del sol no parece demasiado común en amuletos españoles ${ }^{33}$.

Además, no sólo los objetos tenían este valor emblemático, sino que la propia correa que se disponía alrededor del cuello del caballo, a la que van unidos los cascabeles, crecientes, etc.

\footnotetext{
J. Neusner, The Tosefta, translated from the hebrew. New York, 1981, Shabbat 4:5, p. 15.

La alusión a las sandalias en los cascos de los caballos hace referencia, sin duda, a las soleae o hiposandalias, de metal, esparto o junco con que se cubrían los pies de los animales para su protección. Algunos las consideran antecedente de la herradura. Ver al respecto: P. Vigneron, Le cheval dans l'Antiquité Greco-Romaine. Nancy, 1968, t. I, pp. 45-50, t. II, pp. 10-13. M. G. Álvarez Rico, «La cuestión de la Herradura en la Antigüedad», El caballo en la Antigua Iberia, Edit. F. Quesada Sanz y M. Zamora Merchán, Madrid 2003, pp. 145-178.

${ }^{28}$ W. L. Hildburgh, «Cowrie Shells as Amulets in Europe», Folk-Lore, vol. LIII, 1942, p. 184.

${ }^{29}$ G. Brosseau Gardner, «British Charms, Amulets and Talismans, Folk-Lore, LIII, 1942, p. 95.

30 J. Desparmet, 1932, p. 91.

31 Ver al respecto las obras de G. Bellucci, entre otras: Il feticismo primitivo in Italia e le sue forme di adattamento, Perugia, 1919 (reimp. Roma 1983). Paralleles etnographiques: Amulettes. Libye actuelle; Italie ancienne, Perugia, 1915. W. L. Hildbrugh, «Notes on Some Contemporary Portuguese Amulets», Folk-Lore, vol. XIX, 1908, pp. 213-224. Entre los numerosos trabajos de J. Leite de Vasconcellos, ver, Sur les Amulettes Portugaises, Lisbonne, 1892. «Amuletos», O Archeologo portugués, vol. V, 1900, pp. 287- 289.

${ }^{32}$ W. L. Hildburgh, «Lunar crescents as amulets in Spain», Man, 1942, vol. XLII, p. 73.

${ }^{33}$ C. Baroja, Catálogo de la colección de amuletos. Museo del Pueblo Español. Madrid, 1945, p.18.
}

$A E A$, LXXVIII, 2005, 309, pp. 5 a 21 

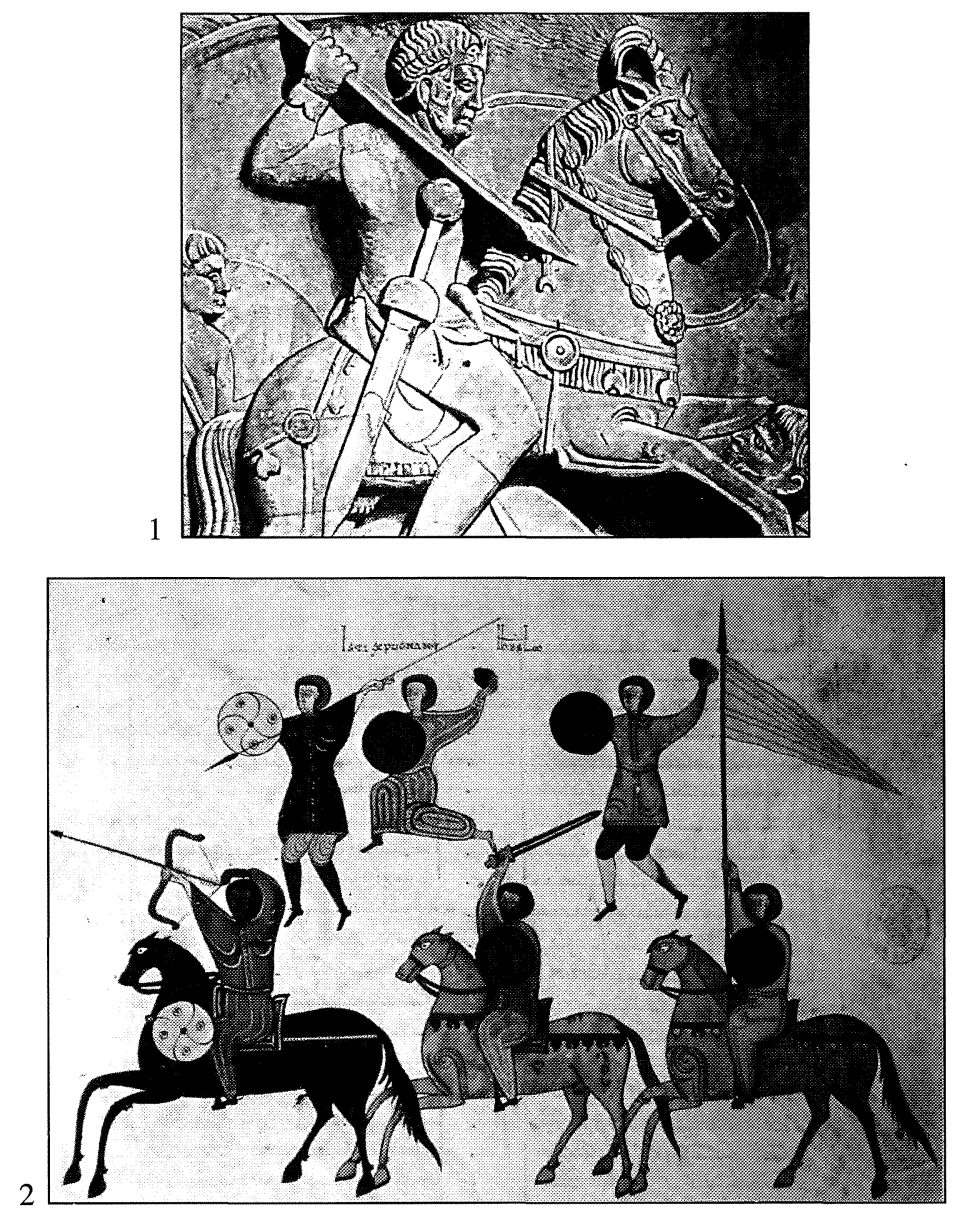

3
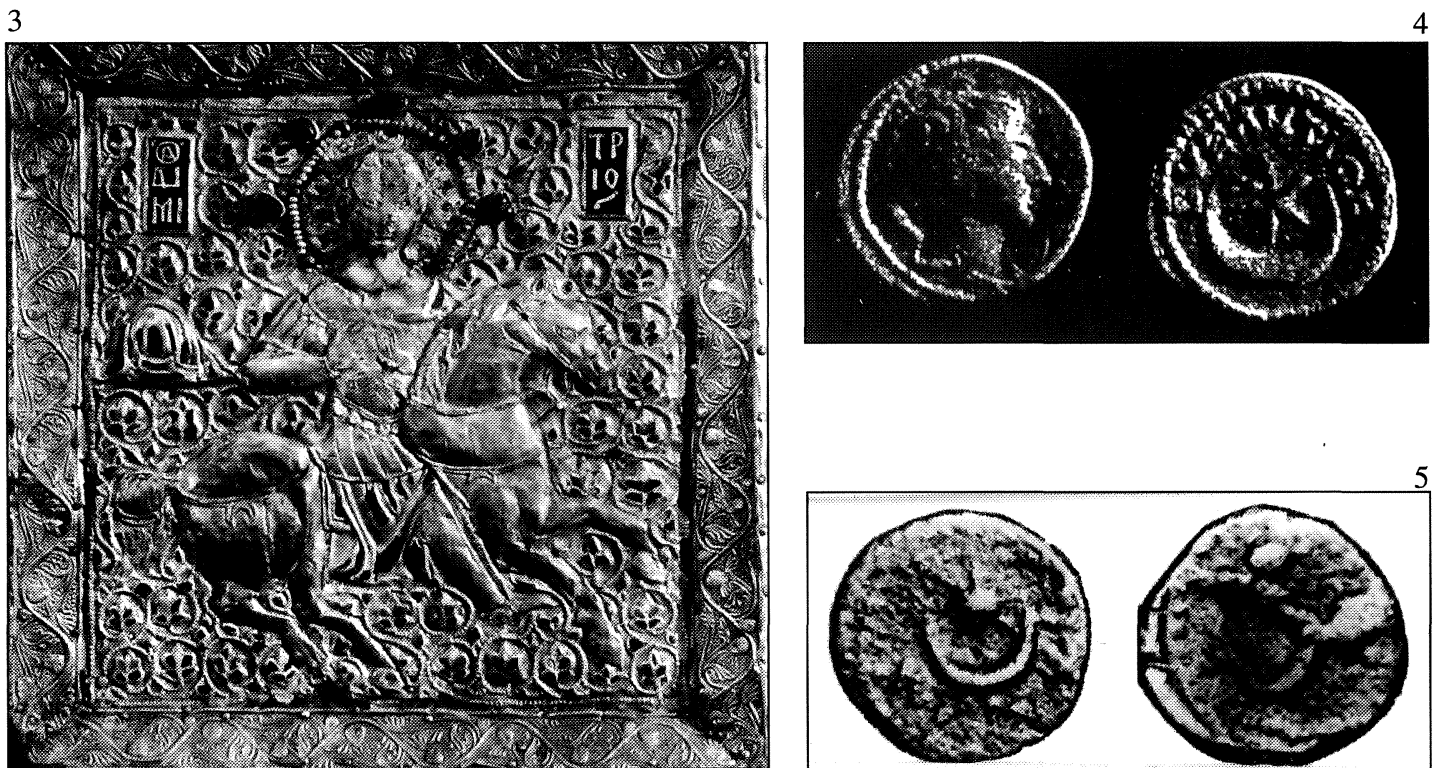

Fig. 1. Monumento funerario de Flavius Bassus (Museo de Colonia).

Fig. 2. Miniatura. Beato de Liébana. Comentario al Apocalipsis de San Juan, S. XI.

Fig. 3. Icono. San Demetrio a caballo. Kunstgewerbemuseum. Berlin. S. XII.

Fig. 4. Moneda con creciente y estrella. Bizancio en época romana, s. I a.C.

Fig. 5. Cuadrante con símbolos astrales y delfín con amorcillo, con las leyendas Saiti y Saitir. Mediados del s. II a.C.

AEA, LXXVIII, 2005, 309, pp. 5 a 21 
suele ir forrada con piel de tejón, cuyos pelos forman un escaso fleco alrededor del borde de la piel. Este forro puede usarse para proteger al animal de la irritación pero es mucho más importante su valor de amuleto ${ }^{34}$. Entre 1420 y 1425 , Enrique de Villena certifica éstos y otros datos más en su Tratado de Fascinación o de Aojamiento. No menciona ninguna clase de preservativos cristianos pero sí prácticas entre los judíos y los musulmanes. Refiriéndose a estos últimos podemos leer: ....Ponen eso mesmo a las bestias cuero con pelo de tasugo en el collar e cabeçadas. E traen horuz, que son nominas pequeñas en las cabeçadas e petrales de los cavallos con çeras e figuras ${ }^{35}$.

En la forma del creciente no siempre es fácil distinguir la referencia a la media luna de la alusión a cuernos, garras, colmillos, etc. de animales que, frecuentemente se unen por la base. Esto llevó a algunos autores ${ }^{36}$ a plantear una evolución, haciendo derivar el creciente lunar de la unión de dos apéndices de animal como, por ejemplo, colmillos de jabalí. Sin embargo, hay quien mantiene que son los dos dientes de jabalí así dispuestos los que imitan a la blanca luna. En este sentido, no hay que olvidar que a la luna estuvieron consagrados diversos animales, entre ellos el ciervo, el perro, el oso y el jabalí, lo que, sin duda, ratifica la fusión de ambos símbolos. La virtud de estos objetos radicaría en el propio diente y, mediante un caso de magia simpática, pasaría al creciente realizado en metal.

Otros, por su parte, plantean para el creciente un origen completamente distinto de su tradicional conexión con los cuernos del poder o con la luna, a la que no conceden especial importancia, y lo hacen derivar de un dibujo del ojo o de una representación de un párpado ${ }^{37}$. La cuestión se clarifica cuando el creciente incluye un rostro de perfil humano dentro de su curva lo que no deja lugar a dudas sobre su relación con el culto lunar. En estos casos, seguramente su empleo como amuleto-talismán vinculado a la creencia de la influencia ejercida por la luna, es más evidente que su identificación con alguna de las grandes divinidades.

A este respecto, conviene recordar que con anterioridad al siglo XIII los amuletos se diferenciaban de los talismanes, considerándose estos últimos, objetos hechos de cualquier material, a los que se atribuían propiedades benéficas o nocivas, que habían sido preparados mediante determinadas ceremonias, con la pretensión de infundir en ellos fuerzas procedentes de los astros, inscribiendo en los mismos determinadas figuras. Por su parte, los amuletos gozaban de supuestas propiedades preventivas no debidas a fuerzas astrales infundidas en ellos por arte humana sino dependientes de otras fuerzas ocultas, inherentes a los elementos que las constituían y a las cualidades de los mismos ${ }^{38}$. Ambas definiciones probablemente nos permiten establecer una diferencia inicial entre el creciente basado en los colmillos de animal unidos por la base y el creciente identificativo con la media luna, considerando, al menos hasta el mundo medieval, al primero como amuleto y al segundo como talismán. Teniendo en cuenta que el éxito del talismán estará garantizado si se hace cuando los signos usados están en ascendente, es fácilmente deducible que el de la luna deberá hacerse mientras está en creciente.

${ }^{34}$ W. L. Hildburgh, «Collectanea. Notes on Spanish Amulets», Flok-Lore, vol. XVII, 1906, p. 461.

35 E. de Villena, «Tratado de Fascinación o de Aojamiento», en Obras Completas, Ed. y prólogo P.M. Cátedra, Madrid 1994, vol. I, pp. 325-341. La palabra horuz, según el sentido que deriva del texto, se refiere a orruzas o amuletos a la manera de jaeces, con figuras e inscripciones, p. 332 .

S. de Covarrubias y Orozco, Tesoro de la lengua castellana o española (1611), Ed. F.C.R. Maldonado y M. Camarero, Madrid 1994, define la palabra aojar como dañar con mal ojo. Cuestion es entre los físicos si hay mal de ojo, pero comunmente esta recibido haber personas que hacen mal con sólo poner los ojos en otra, especialmente si es con ira o con envidia, p. 101.

${ }^{36}$ W. Ridgeway, «The Origin of the Turkish Crescent», Journal of the Royal Anthropological Institute of Great Britain and Ireland, vol. 38, 1908, pp. 241- 258.

37 E. Westermarck, 1926, vol. I, p. 473.

38 A. Cardoner Planas, «Los talismanes y la patología medieval», Rev. de Dialectología y Tradiciones Populares, 1958, pp. 70-77.

AEA, LXXVIII, 2005, 309, pp. 5 a 21 

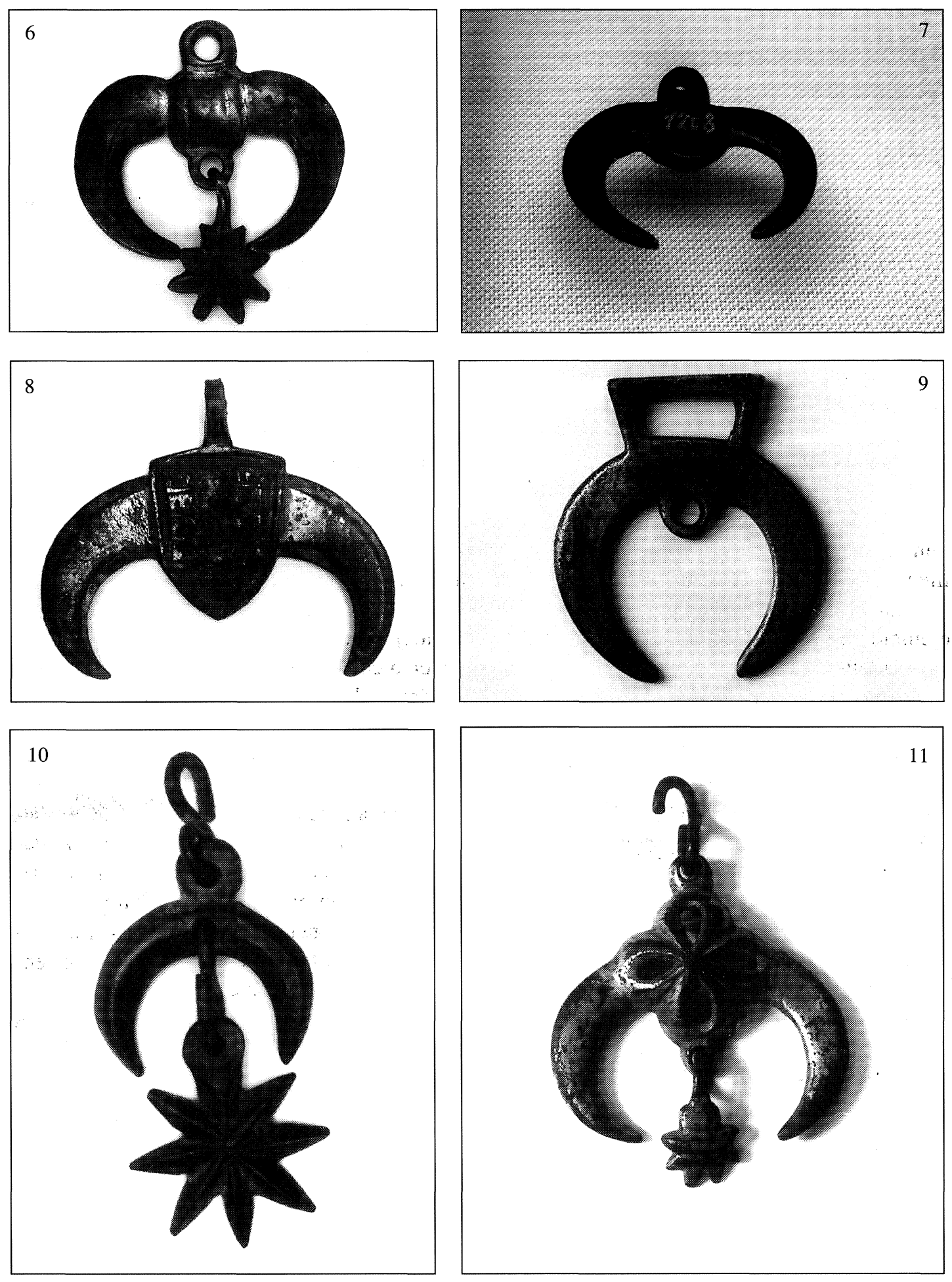

Fig. 6. Pinjante. Instituto Valencia de D. Juan (Madrid). S. XIII-XIV.

Fig. 7. Pinjante. Museo Arqueológico. Granada. (75-125).

Fig. 8. Pinjante. Instituto Valencia de D. Juan (Madrid). Mediados s. XIV.

Fig. 9. Pinjante. Instituto Valencia de D. Juan (Madrid). S. xIII.

Fig. 10. Pinjante. Instituto Valencia de D. Juan (Madrid). S. XIII-XIV.

Fig. 11. Pinjante. Instituto Valencia de D. Juan (Madrid). S. XIV.

$A E A$, LXXVIII, 2005, 309, pp. 5 a 21 
Esto explicaría el elevado número de éstos frente a la representación de otras fases lunares como el menguante o la luna llena ${ }^{39}$.

En la mentalidad popular la forma de creciente cumpliría las dos funciones - amuleto y talismán-, produciéndose una simbiosis en el aspecto formal así como en los efectos producidos, la prevención contra el mal de ojo y la protección ante el influjo lunar, influencias que se consideran prioritarias. En este sentido, durante la décimo tercera centuria empiezan a gestarse cambios importantes y los escritores (Guillermo de Auvernia, Alberto Magno) comienzan a ver la magia natural como una alternativa a las formas diabólicas. Esta noción de magia natural se asienta en la cultura europea durante los siglos XIV y xv ${ }^{40}$.

Además, con frecuencia, la forma de creciente ve fortalecido su poder ya que sirve como elemento básico o forma parte de amuletos más complejos, compuestos de una mano abierta (la conocida como mano de Fátima), de una mano en forma de higa, una estrella, la rosa de Jericó, el sol, la cimaruta, etc. Con un emblema como el puño situado entre los cuernos aparece como protección en los caballos de tiro ingleses ${ }^{41}$.

Otro aspecto complejo que, aunque de forma somera, es necesario referenciar es la tradicional vinculación del creciente con el mundo oriental. El creciente y la estrella fueron el símbolo constante de Bizancio desde los días en que aparecen en las monedas bizantinas. Una moneda de bronce de Bizancio en época romana (s. I a.C.) (Fig. 4) muestra en el anverso según unos el busto de un emperador, según otros la cabeza de Artemisa con carcaj al hombro, mientras el reverso lo ocupa un creciente con estrella y la inscripción BYZANTION ${ }^{42}$.

Sin embargo, creciente y estrella aparecen también en monedas de otras latitudes como, por ejemplo, Egipto, sin olvidar España. Una moneda alejandrina que muestra en el anverso la cabeza laureada de Augusto a derecha, ocupa su reverso con una media luna y una estrella de ocho puntas. Emparenta con una serie imperial que data del año 19 a.C. y los símbolos se interpretan como Selene y Helios, las dos divinidades de la luz ${ }^{43}$. En el ámbito español, la iconografía monetal feno-púnica incluye abundantes tipos zoomorfos así como símbolos astrales. Numerosos son los ejemplos de acuñaciones ibéricas y celtibéricas donde el creciente, el menguante y la estrella se combinan entre sí y con distintos animales, especialmente el toro, el caballo y el jabalí. Por su similitud con algunas piezas que analizaremos recogemos un cuadrante con símbolos astrales y amorcillo sobre delfín (Fig. 5), correspondiente a mediados del siglo II a.C. ${ }^{44}$. Conviene llamar la atención, asimismo, sobre un posible uso mágico ya que se observa que algunas monedas han sido perforadas para ser colgadas como amuletos. En ciertos casos parecen estar vinculadas a la existencia de un culto al toro y a la vaca y, en este sentido, Diodoro habla de una leyenda que menciona un culto a las vacas entre los iberos.

Esta amplia difusión de los símbolos hace pensar en un culto generalizado a los astros y a determinados animales, sin duda muy anterior en el tiempo, en los que ven efectos tanto bene-

${ }^{39}$ J. Desparmet, 1932, p. 98. La tradición cuenta que un día la luna se enorgullecía de su brillo y que Dios para castigarla la condenó al menguante mensual, de manera que sólo recupera su luz para perderla de nuevo (Nozhat el Madjalis, I, 120).

${ }^{40}$ R. Kieckhefer, 1992, pp. 20-21.

${ }^{41}$ R. T. Günther, M.A., F.L.S., 1905, p. 141.

42 B. V. Head, Historia Nvmorvm. A Manual of Greek Numismatics. (ed. orig. 1886) Chicago, 1967, p. 269. W. Ridgeway, 1908, p.241, p. XIX, fig. 2. Estos serían los símbolos de Artemisa como diosa de la luna, identificada con Hekate, a quien, según Hesiquio de Mileto (s. vi d.C.), los bizantinos dedicaron una estatua en memoria de la luz milagrosa que ella una vez proporcionó para alumbrar el firmamento durante un ataque nocturno de los macedonios a la ciudad, revelando la proximidad del enemigo.

${ }^{43}$ M. Spoerri, Monnais provinciales de l'Orient Romain, Lausanne 1996, p. 97, n. ${ }^{\circ} 84$

${ }^{44}$ C. Alfaro Asins y otros, Historia monetaria de Hispania Antigua, Madrid 1998, p. 134, fig. 118; p. 261, fig. 205; pp 269-270, figs. 269-270, p. 271, fig.221. M. Ruiz Trapero, Las monedas hispánicas del Instituto Valencia de Don Juan, Madrid, 2000, vol. I, n. ${ }^{\circ} 179$, p. 96; n. ${ }^{\circ} 712$, p. 188; n. ${ }^{\circ} 1323$, p. 287 ; n. ${ }^{\circ} 1992$, p. 397.

AEA, LXXVIII, 2005, 309, pp. 5 a 21 
ficiosos como nocivos, tratando de contrarrestar estos últimos. Ya en época posterior, en España, la estrella de seis puntas se registra en un dirhem de época de Hisam II y aparece también la marca en forma de creciente, combinada con otro símbolo, célebre entre los talismanes del mundo judío del que lo tomaron los musulmanes, como es el sello de Salomón, en acuñaciones de Madinat-al-Zahra $(340 \mathrm{H})$, si bien parece ser bastante frecuente en acuñaciones anteriores ${ }^{45}$.

Del mismo modo, entrar en la cuestión de los orígenes del creciente y su derivación bien de los cuernos de los animales, bien de la representación de diversas fases lunares, se nos antoja tarea de difícil resolución. Sin pretender ahondar en la cuestión, la mera observación de algunas representaciones del mundo antiguo, llevan a pensar, según se ha sugerido anteriormente, en una simbiosis paulatina de las dos formas con distinta intencionalidad en origen, máxime teniendo en cuenta que muchas de las funciones asignadas a estos amuletos para combatir efectos no deseados eran comunes.

- El significado de los cuernos como símbolo de fuerza, poder y vigor está presente prácticamente en todas las culturas de la Antigüedad, donde especialmente el toro tuvo gran protagonismo. Los asirios utilizaban la tiara de cuernos como atributo de la divinidad. En Egipto, el Libro de los Muertos (cap. CLXV) denomina al propio Amón, Señor del doble cuerno. Apolo Karneios es el dios poderoso, protector de los animales de cuernos. En Delos existía un altar llamado el Keraton, totalmente formado por cuernos de bueyes y de cabras entrelazados. La tradición árabe designa a Alejandro como el de los dos cuernos, lo que, habitualmente, se interpreta como signo de su poder hacia oriente y occidente. Además, hay que tener en cuenta también que Alejandro, declarado hijo de Amón por el oráculo, tomó como emblema los dos cuernos de carnero que eran los principales atributos del dios, legitimándose como sucesor de los antiguos faraones que llevaban este emblema ${ }^{46}$.

Numerosas son las referencias bíblicas de las que extraemos sólo algunas. En el Libro de los Reyes $(22,11)$ se lee: Sedecias, hijo de Kenaaná se había hecho unos cuernos de hierro y decía: «Así dice Yaveh: con estos acornearás a Aram hasta acabar con ellos». En las bendiciones de Moisés a José (Deuteronomio 33,17) se dice: Primogénito del toro, a él la gloria, cuernos de búfalo sus cuernos; con ellos acornea a los pueblos todos juntos hasta los confines de la tierra. Del mismo modo, el Exodo (27,1-2), al plantear las normas referentes a la construcción del santuario, habla de los cuernos en los cuatro ángulos del altar. El cuerno fue también utilizado para la unción de los reyes, El sacerdote Sadoq tomó de la Tienda el cuerno del aceite y ungió a Salomón...(Libro de los Reyes 1,39). Esta práctica se mantuvo durante la Edad Media, simplemente recordemos la conocida miniatura del Antifonario Mozárabe (fol. 271v, Catedral de León). Del mismo modo, los cuernos con que, tradicionalmente, se culmina la cabeza de Moisés se suponían símbolo de fuerza y poder, considerados imagen de los rayos luminosos. Así pues, los cuernos sin duda ejercen un efecto positivo, transmitiendo poder, vigor etc, y, además, preservan contra el mal de ojo que, junto a la influencia lunar, según se ha señalado, son las dos supersticiones más importantes que afectan a personas, animales y objetos ${ }^{47}$.

Dentro de la dificultad que entraña deslindar en el creciente la forma basada en la unión de dos cuernos de la derivada de la media luna, en la selección de piezas que aquí se recogen se pueden observar especialmente dos que responderían al primer supuesto. Una pieza del Instituto Valencia de Don Juan de Madrid (Inv. 5729, Fig. 6) muestra con cierta precisión la

45 J. J. Rodríguez Lorente, «El sello de Salomón en un dirhem inédito de Abd-al Rahman III», Al-Qantara, vol. XII, 1991, pp. 277-279.

${ }^{46}$ R. Guenon, Símbolos fundamentales de la Ciencia Sagrada. Barcelona 1995, pp. 149-152.

${ }_{47}$ Ver entre otros: E. Westermarck, 1926, especialmente, vol. I, Cap. VIII.

F. T. Elworthy, The Evil Eye: The Origins and Practice of Superstition, London 1895 (reimp. N. York 1958).

$A E A$, LXXVIII, 2005, 309, pp. 5 a 21 
unión de los dos cuernos por su base, dejando en el centro una forma rectangular que simula la testa de la que nacerían. Ésta va provista de dos salientes circulares perforados, de modo que el superior sirve para su suspensión y del inferior cuelga una estrella de ocho puntas ${ }^{48}$. La incorporación de ésta, sin embargo, podría llevar a pensar en la vinculación de dos formas astrales en cuyo caso habría que interpretar los cuernos, cuya estructura es indudable, como una asimilación a los de la luna y diferenciarlo así del creciente lunar.

Se trata de una tipología estrechamente vinculada al mundo romano y que ha experimentado escasa variación. A este respecto, Bishop ${ }^{49}$, de manera acertada, incluye entre las lunulae un tipo de variantes exóticas y, entre las más tempranas sitúa los boar's tusk pendants (colgantes de dientes de jabalí) que se encuentran en contextos romanos y célticos. El Museo Arqueológico de Granada posee uno (Inv.1208, Fig. 7), en este caso sin estrella, que entró a formar parte de la colección en 1880, donado por la Comisión de Monumentos. Aunque de procedencia desconocida, se sitúa cronológicamente entre los años 75 y 124. Otro ejemplo se puede encontrar en el Museo de Mérida (Inv. 29.277) ${ }^{50}$. Se podría, tal vez, plantear una ligera diferencia en la forma penetrante y aguda de la representación de los cuernos de animal.

Otro curioso pinjante del Instituto Valencia de D. Juan de Madrid (Inv. 5584, Fig. 8) en forma de creciente está diseñado a base de dos penetrantes cuernos unidos por la base. En el centro incluye un escudo triangular acabado en punta que integra la anilla de sujeción. En su campo alberga un castillo de dos torres almenadas que irían sobre fondo de gules. Supone la síntesis del tradicional valor de amuleto- talismán con la idea de posesión del animal o, tal vez, dado el motivo de enorme difusión como es el castillo, simplemente se trata de un emblema heráldico utilizado con finalidad ornamental, algo muy habitual en el contexto bajomedieval.

El conservado en el Museo Episcopal de Vic ( MEV 9147) podría considerarse como una evolución del llamado trífido ${ }^{51}$, estrechamente unido con la lúnula con colgantes internos. Hay una amplia gama de variaciones pero la mayoría de las versiones tienen un lóbulo central decorado en forma de hoja. Motivo común es, asimismo, la hoja de encina flanqueada por bellotas terminales.

Formas de creciente, solas o unidas a la estrella (símbolo solar) encontramos en otra serie de pinjantes más o menos decorativos. El más sencillo, sin ninguna clase de ornamentación (Inv. 5714, Instituto Valencia de D. Juan, Madrid, Fig. 9), va provisto de un asa rectangular en la parte central exterior y un saliente circular en el interior, de donde colgaría una pieza, hoy desaparecida, posiblemente una estrella, a juzgar por análogos ejemplares. En otras ocasiones (Inv. 5717, Instituto Valencia de Don Juan, Madrid, Fig. 10) está integrado por la articulación de dos piezas de similares proporciones. La superior, en forma de creciente liso, va provista de un saliente circular perforado en la parte externa, por donde se suspendía, mientras un agujero, practicado en el propio cuerpo, sirve para enganchar una estrella de ocho puntas colgante. En este caso, los dos símbolos tienen la misma importancia si nos atenemos a sus dimensiones.

La divisa de cuatro pétalos dentro del cuerpo del creciente es lo más significativo del pinjante que analizamos a continuación, asimismo perteneciente a la colección del Instituto Valencia de D. Juan de Madrid (Inv. 5731, Fig. 11). La flor de cuatro pétalos calada, que destaca en el centro, va provista de dos salientes, uno para la suspensión y otro para articular una pequeña estrella de ocho puntas, que, es evidente, tiene una consideración menor. Sobre el signi-

\footnotetext{
${ }^{48}$ La similitud con el publicado por W. L. Hildburgh, 1942, p. 76, D10, es evidente.

49 M. C. Bishop, 1988 , p. 98 , fig. 48 , 9s.

50 J. L. de la Barrera Antón y A. Velázquez Jiménez, «Amuletos romanos de Mérida», en Homenaje a Samuel de los Santos, Murcia, 1988 , p. 212 , fig. 3 , n. $^{\circ} 1$. Se relaciona con el culto a la luna.

${ }^{51}$ M. C. Bishop, 1988, tipo I, p. 96, fig. 43.
}

AEA, LXXVIII, 2005, 309, pp. 5 a 21 


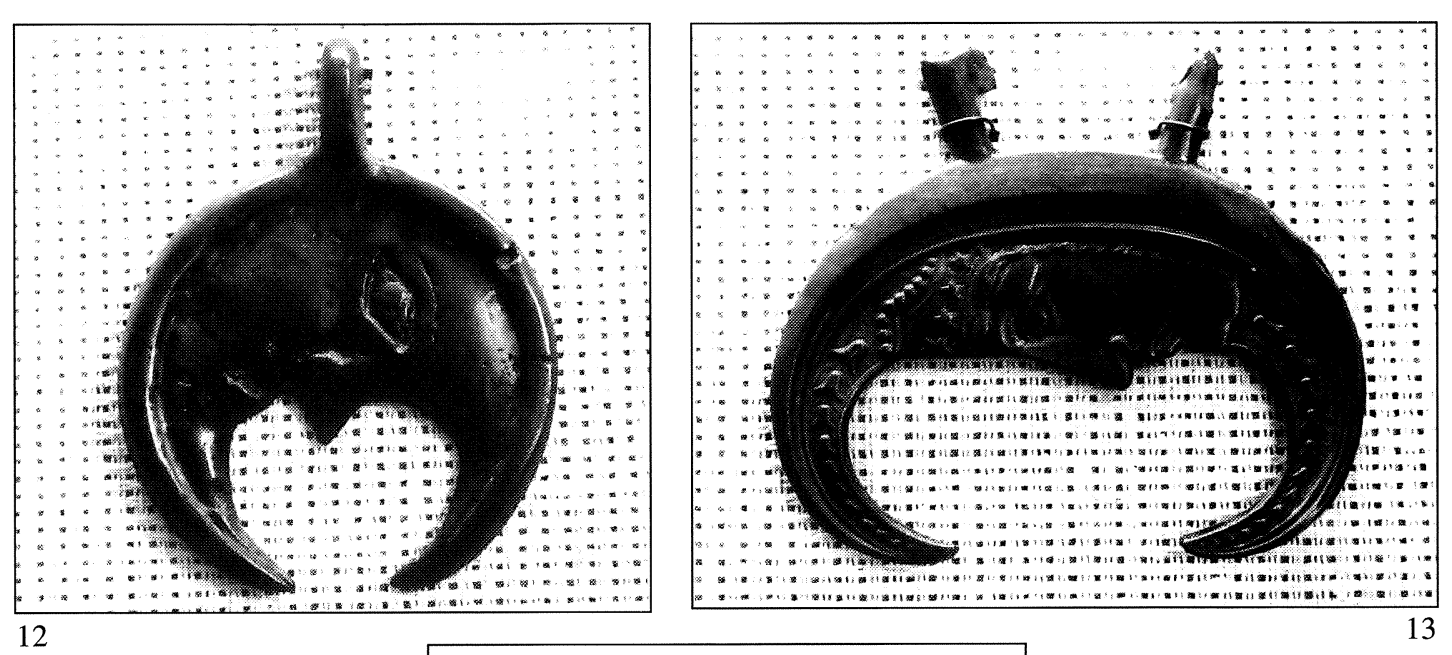

14
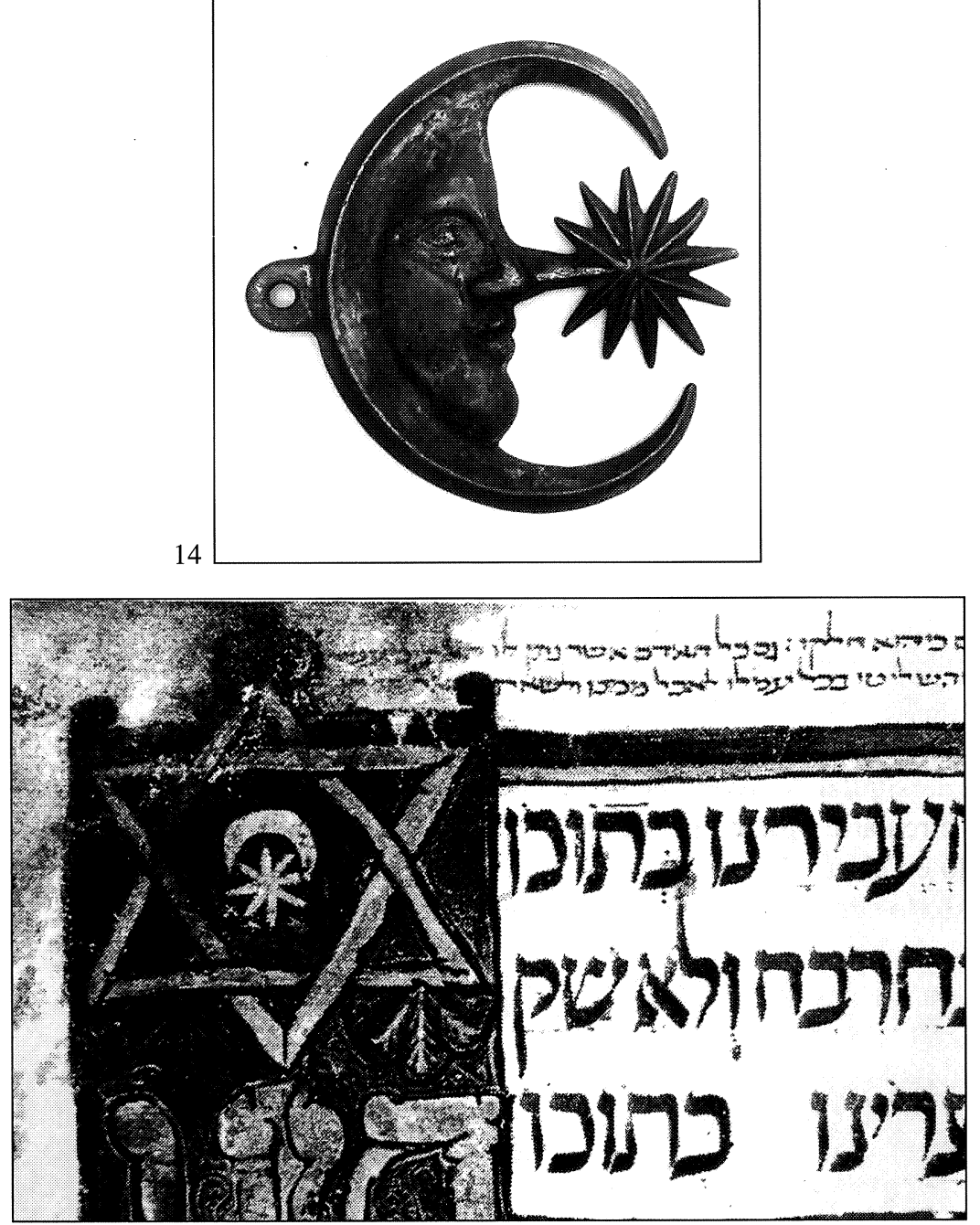

Fig. 12. Pinjante. Museo Lázaro Galdiano. Madrid. S. XIII-XIV.

Fig. 13. Pinjante. Museo Lázaro Galdiano. Madrid. S. XIv.

Fig. 14. Pinjante. Instituto Valencia de D.Juan (Madrid). S. xiv.

Fig. 15. Creciente con estrella dentro de un escudo de David. Mocatta Haggadah (Islas Británicas). Castilla hacia 1300. Fol. 40r.

$A E A$, LXXVIII, 2005, 309, pp. 5 a 21 
ficado de la flor en principio desconocido, Hildburgh ${ }^{52}$ apuntó una posible relación con el símbolo solar que encontramos asociado a un buen número de amuletos crecientes españoles. Asimismo, tuvo en cuenta que su aparición junto al monograma que representa la Virgen y su forma cruciforme, asociada a la cruz cristiana, le asignaba virtudes protectoras. No obstante, parece tratarse de la conocida como rosa de Jericó, a la que se ha hecho alusión con anterioridad. Un tipo de helecho que crece en abundancia en ciertas zonas del desierto de Arabia y en las riberas del Mar Rojo. Se considera símbolo de eternidad y se conoce como flor sagrada de la resurrección por su facultad de florecer de nuevo una vez seca ${ }^{53}$. Posiblemente en los primeros siglos de la Edad Media, algunos viajeros la llevaron hasta Jericó, de donde deriva su nombre. En la tradición europea, su inclusión se remonta al siglo xIII y es en Francia donde se le atribuyen poderes en el diagnostico del embarazo, favoreciendo los nacimientos. Seguramente, por esta razón, se asocia con la figura de la Virgen y, a veces, se la designa como flor de María o rosa de la Madonna. Durante el medievo se tenía la creencia de que absorbía las energías negativas, transformándolas en positivas y, a partir del siglo xIII, se generaliza en los mercados populares especialmente por su poder de adivinación del futuro y para alejar el mal de ojo ${ }^{54}$.

Una pieza con el mismo perfil, de la que colgaría, previsiblemente, una estrella, con un abombamiento central a modo de capullo, podemos encontrar en el Museo de Jerez de la Frontera. El interés que presenta se cifra especialmente en el hecho de que apareciese junto a cerámica árabe de tiempos del Califato e incluso posterior ${ }^{55}$.

Tradicionalmente la figuración de la luna, con o sin rasgos humanos, se relaciona con el mundo morisco, sin embargo, como hemos visto, su aparición es muy anterior. En España, se usó, sin duda, antes de la invasión musulmana y su pervivencia puede ser debida a la herencia romana del mundo bizantino ${ }^{56}$. San Isidoro, al referirse a los adornos de las cabezas de las mujeres dice: lunulae sunt ornamenta mulierum, in lunae similitudine bullulae aureae dependentes (las lunulae son adornos femeninos: son bolitas de oro que cuelgan a manera de lunas $)^{57}$.

La luna con rasgos humanos es otra forma presente entre los pinjantes y, en este caso, no deja lugar a dudas sobre su significado. El Museo Lázaro Galdiano de Madrid conserva dos ejemplares de desigual factura. Uno, de rasgos muy sencillos, marca el perfil mediante un saliente central que simula la nariz mientras el ojo está resuelto a base de incisiones, así como la boca (Fig. 12). El otro, de mayor riqueza decorativa y cuidado tratamiento, dibuja perfectamente los rasgos del rostro cuyo cabello asoma por debajo de una corona con perlas y estrellas, mientras los cuernos de la luna se cubren con una hilera de campanillas ${ }^{58}$ (Fig. 13). Cuando la luna adopta perfil humano, la estrella se proyecta como prolongación de su nariz. Es el caso de un ejemplar en el Instituto Valencia de D. Juan de Madrid (Inv. 5580, Fig. 14). La luna tratada como rostro figura con frecuencia en la pintura musulmana. Los poetas persas la han cantado como la suprema encarnación del encanto femenino. En Occidente se represento, al igual

\footnotetext{
${ }^{52}$ W. L. Hildburgh, 1913, p. 65. «Notes on Spanish Amulets (Fourth Series)», Folk-Lore, vol. XXVI, n. ${ }^{\circ} 4,1915$, p. 413; 1942, pp. 74-75.

53 S. Keribal, El lado humano de una leyenda. La Rosa de Jericó, Bilbao, 1999, p. 182.

${ }^{54}$ B. Lavall, Los prodigios de la rosa de Jericó, Barcelona 1996, p. 24.

55 M. Esteve Guerrero, «Excavaciones de Asta Regia (Mesas de Asta, Jérez)», Campaña de 1942-43, Acta Arqueológica Hispánica, III, Madrid, 1945, p. 48, lám. XXIV. Según información que agradezco a R. González, Directora del Museo, es de bronce, $\mathrm{N}^{\circ} \mathrm{R}: \mathrm{E}$ : $401, \mathrm{~N}^{\circ}$ I.G.: 587 ,y para su adscripción a época islámica no hay ningún otro dato ni en memoria ni en diario de campo.

56 A. Soler del Campo, «Arreos y jaeces para caballerías en Al-Andalus», en Al-Andalus y el caballo (Claustro de Santo Domingo de Jerez, abril-junio, 1995). Barcelona, 1995, p. 88.

57 San Isidoro de Sevilla, 1983, vol. II, pp. 484-485.

58 M. L. ${ }^{a}$ Martín Ansón, 1986, p. 62.
}

$A E A$, LXXVIII, 2005, 309, pp. 5 a 21 
que el sol, bajo la forma de bustos dentro de un disco y adoptaron también el rango de plantas parlantes ${ }^{59}$.

En ocasiones la media luna, como se ha señalado, se combina con una estrella o símbolo solar, de distinto número de puntas, en una composición cercana a la de las monedas referenciadas con anterioridad. Lunas crecientes con o sin estrellas de variado número de puntas, aparecen con frecuencia en las Cantigas, especialmente en los estandartes que portan sus personajes ${ }^{60}$. Con una estrella de ocho puntas, dentro de un Escudo de David, que asimismo tiene carácter mágico, aparece representada en el margen de un Mocatta Haggadah (Islas Británicas), sin ilustraciones bíblicas pero con numerosas decoraciones en el texto, que pertenece a la escuela castellana hacia $1300{ }^{61}$ (Fig. 15). El mismo iconograma encontramos en las banderas de la batalla de la Higueruela (victoria de Juan II de Castilla contra Muhammad VIII de Granada, 1431), en las pinturas de El Escorial, donde se acompaña de signos esotéricos.

Esta asociación, en diversos países musulmanes, es tratada como imagen poética del Cielo o Paraíso ${ }^{62}$. Estrellas y crecientes son elementos básicos para combatir diferentes males, de modo especial los derivados del mal de ojo, ya que con su brillo impiden la acción de la vista. El propio Profeta ha puesto de relieve ante sus fieles estas virtudes de que goza el creciente: $\mathrm{el}$ Musulmán al ver la luna nueva, pronunciará la fórmula «Alabanza a Dios» y recitará siete veces la Fatiha, por favor divino, no habrá de quejarse de los males de la fascinación en el curso de este mes (Nozhat el madjalis, I, 131) ${ }^{63}$.

La presencia del creciente sólo o combinado con la estrella es habitual en distintas manifestaciones artísticas y en numerosos objetos que, en su momento, tuvieron un carácter eminentemente práctico. En el contexto español de la edad media, según ha podido comprobarse, son formas comunes a las tres culturas y su pervivencia, prácticamente sin cambios, se extiende a lo largo de la historia hasta nuestros días. No hay que olvidar el extraordinario uso que de amuletos y talismanes, con estas y otras formas, hicieron los miembros de la realeza y la nobleza a lo largo de los siglos XVI y XVII, para lo que simplemente basta con contemplar sus retratos. En España, presumiblemente igual que en otros países —en especial Gran Bretaña-, a la vista de las fuentes gráficas y las piezas conservadas, se observa la escasa evolución en sus tipologías. Al menos hasta la segunda mitad del siglo xx, todavía en numerosas regiones españolas se seguían fabricando este tipo de piezas, con similares finalidades y, prácticamente, idénticas formas.

Utilizadas en amuletos, especialmente por madres e hijos, su proceso de preparación les confiere el carácter, asimismo, de talismán. Se fabrican en diversos metales y los de hierro los fabrica el herrero del pueblo, y para que tengan la virtud que se les atribuye, deben comenzar a trabajarlos el miércoles de Ceniza, por ser el primer día de Cuaresma, siguiendo la tarea durante todos los viernes hasta el último cuaresmal, en que ya debe estar terminado para poderlo poner en el monumento de Jueves Santo de donde se retira el Viernes al deshacerlo, y entonces ya se puede usar ${ }^{64}$.

\footnotetext{
59 J. Baltrusattis, La Edad Media Fantástica, Madrid, 1983, p. 139.

${ }^{60}$ En la Cantiga CXXV la estrella de cinco puntas se asocia a una alegoría de la liberación de los demonios, estampa muy sugestiva en la que aparecen otros signos curativos y esotéricos, como estrellas de seis y ocho puntas y barras en aspa con circulillos o varias pseudoletras, dotadas también de círculos. B. Pavón Maldonado, «Arte, símbolo y emblemas en la España Musulmana», Al-Qantara, 1985, vol. 6, p. 441.

${ }^{61}$ B. Narkiss, Hebrew illuminated manuscripts in the British Isles. The Spanish and Portuguese Manuscripts. Jerusalem and London, 1982, p. 52, pl. XXIV, fig. 113

${ }^{62}$ Enciclopedie de l'Islam, Paris, 1965, voz Hilal, t. III, pp. 390-398.

${ }_{63}$ J. Desparmet, 1932, p. 98.

${ }^{64}$ J. R. Fernández Oxea, «Amuletos lunares, en Cáceres», Rev. De Dialectología y Tradiciones Populares, 1952, t. VIII, Cuaderno $3 .^{\circ}$, pp. 3-20.

«Amuletos lunares toledanos», Rev. De Dialectología y Tradiciones Populares, 1965, t. XXI, n 1-2, pp. 143-163 (pp. 147-148).
}

AEA, LXXVIII, 2005, 309, pp. 5 a 21 